\title{
Precise Toxigenic Ablation of Intermediate Cells Abolishes the "Battery" of the Cochlear Duct
}

\author{
Hyo Jeong Kim, ${ }^{1}$ Michael Anne Gratton, ${ }^{2}$ Jeong-Han Lee, ${ }^{1}$ Maria Cristina Perez Flores, ${ }^{1}$ Wenying Wang, ${ }^{1}$ \\ Karen J. Doyle, ${ }^{1}$ Friedrich Beermann, ${ }^{3}$ Michael A. Crognale, ${ }^{4}$ and Ebenezer N. Yamoah ${ }^{1}$ \\ ${ }^{1}$ Center for Neuroscience, Program in Communication Science, University of California-Davis, Davis, California 95618, ${ }^{2}$ Otolaryngology-Head, Neck \\ Surgery, St. Louis University, St. Louis, Missouri 63108, ${ }^{3}$ Swiss Institute for Expérimental Cancer Reverché, CH-1015, Epalinges, Switzerland, and \\ ${ }^{4}$ Departments of Psychology and Biomedical Engineering, University of Nevada, Reno, Nevada 89557
}

The extracellular potential of excitable and nonexcitable cells with respect to ground is $\sim 0 \mathrm{mV}$. One of the known exceptions in mammals is the cochlear duct, where the potential is $\sim 80-100 \mathrm{mV}$, called the endocochlear potential (EP). The EP serves as the "battery" for transduction of sound, contributing toward the sensitivity of the auditory system. The stria vascularis ( $\mathrm{StV}$ ) of the cochlear duct is the station where the EP is generated, but the cell-specific roles in the StV are ill defined. Using the intermediate cell (IC)-specific tyrosinase promoter, under the control of diphtheria toxin $(D T)$, we eliminated and/or halted differentiation of neural crest melanocytes after migration to the StV. The ensuing adult transgenic mice are profoundly deaf. Additionally, the EP was abolished. Expression of melanocyte early marker and Kir4.1 in ICs precedes the onset of pigment synthesis. Activation of DT leads to loss of ICs. Finally, in accord with the distinct embryology of retinal pigmented cells, transgenic mice with toxigenic ablation of neural crest-derived melanocytes have intact visual responses. We assert that the tyrosinase promoter is the distinct target for genetic manipulation of IC-specific genes.

\section{Introduction}

The cochlear duct of the inner ear is one of the known compartments in mammals where an extracellular DC potential (endocochlear potential $[\mathrm{EP}]$ of $\sim 80-100 \mathrm{mV}$ ) has been measured (Salt et al., 1987; Nin et al., 2008), and it contributes significantly to the acute sensitivity of the auditory system (Hibino et al., 2010). Georg von Bekesy first recorded the EP (Von Bekesy, 1952), and subsequent extensive studies have demonstrated that this remarkable potential is generated by three layers of cells in the stria vascularis $(\mathrm{StV})$ of the cochlear duct (Salt et al., 1987; Takeuchi et al., 2000). These cells include marginal, intermediate, and basal cells (MCs, ICs, and BCs, respectively). However, there has been longstanding debate on the origin of cells of the $\mathrm{StV}$ and their specific roles in conferring the EP. Recent evidence touts that the EP is generated by the flux of $\mathrm{K}^{+}$ions from the apical aspects of ICs into a $\sim 15$-nm-space, called interstrial space (IS) (Hibino et al., 2010) and rapid uptake of $\mathrm{K}^{+}$by transporters in MCs. The dynamic, unidirectional flow of $\mathrm{K}^{+}$is maintained by the flux of $\mathrm{K}^{+}$through Kv7.1 channels decorating the apical membrane of MCs (Barhanin et al., 1996). Moreover, the production of melanin and its precursors, such as L-DOPA, has been

Received May 21, 2013; revised July 16, 2013; accepted Aug. 7, 2013.

Author contributions: E.N.Y. designed research; H.J.K., M.A.G., J.-H.L., M.C.P.F., K.J.D., M.A.C., W.W., and E.N.Y. performed research; K.J.D., F.B., and E.N.Y. contributed unpublished reagents/analytic tools; H.J.K., M.A.G.,M.C.P.F., M.A.C., W.W., and E.N.Y. analyzed data; E.N.Y. wrote the paper.

This work was supported by the National Institutes of Health Grant DC007592 to E.N.Y. We thank members of our laboratory for comments on the manuscript.

The authors declare no competing financial interests.

Correspondence should be addressed to Dr. Ebenezer N. Yamoah, Center for Neuroscience, Department of Anesthesiology, University of California-Davis, 1544 Newton Court, Davis, CA 95618. E-mail: enyamoah@ucdavis.edu. DOI:10.1523/JNEUROSCI.2147-13.2013

Copyright $\odot 2013$ the authors $\quad 0270-6474 / 13 / 3314601-06 \$ 15.00 / 0$ implicated in age-related and noise-induced hearing loss, and it is uncertain whether ICs confer diverse or unique roles in the inner ear (Murillo-Cuesta et al., 2010).

Here, we took advantage of ICs as melanocytes and used the melanocyte-specific promoter, tyrosinase promoter, to drive the expression of the suicide gene diphtheria toxin $(D T)$ to precisely ablate or halt differentiation of neural crest melanocytes after migration to the $\mathrm{StV}$ in mice. We found that toxigenic ablation of ICs results in profound deafness. These findings reveal that expression of melanocyte early marker (MelEM) in ICs precedes the onset of pigment synthesis, and it is followed by a downregulation in fully differentiated melanocytes. Moreover, the expression of Kir4.1 channels in ICs occurs at low levels during the final stages of cell migration and differentiation. Activation of $D T$ results in loss of ICs and the retraction of MC processes. Consistent with the etiology and embryology of pigmented cells in the retina, mice with toxigenic ablation of neural crest-derived melanocytes have normal retinal responses.

\section{Materials and Methods}

Subjects. All experiments were performed under a protocol approved by the University of California Institutional Animal Care and Use Committee. The subjects included 375 tyrosinase (tyr) (199 males and 176 females) enhancer with attenuated diphtheria toxin A transgenic (TG) mice ( $\operatorname{tyr}(h s 3.6 / 6.1)-D T-A)$, heretofore denoted as (tyr-DT-A), and their age-matched wild-type (WT) control C57 mice, 3-16 weeks old (Camacho-Hubner and Beermann, 2001). Animals were housed under regular $12 \mathrm{~h}$ light/dark cycle and in sound-attenuated chambers with food and water. To reduce age-related complications of the results, we conducted the experiments using age-matched controls and restricted the experiments to 3- to 16-week-old mice (Erway et al., 1993). 
Auditory brainstem response (ABR). ABR waveforms were recorded from anesthetized mice, as previously described (Nie et al., 2005), from broadband clicks and pure tones $(8,16$, and $32 \mathrm{kHz}$ ). The threshold of hearing was determined as the lowest intensity of sound required to elicit a characteristic waveform.

Distortion Product Otoacoustic Emissions (DPOAE). Mice were anesthetized with a mixture of ketamine and xylazine, and DPOAE was measured as described previously (Wang et al., 2009).

Endocochlear potential measurement. The EP was measured as described previously (Nie et al., 2005). The recording electrode passed through the spiral ligament of the lateral wall into the scala media. The potential difference between the scala media and the reference electrode was recorded.

Electroretinography (ERG). Mice were darkadapted for $\sim 2 \mathrm{~h}$ before testing occurred. Mice were anesthetized using ketamine $(1 \mathrm{mg} / \mathrm{g})$ and xylazine $(0.4 \mathrm{mg} / \mathrm{g})$. Pupils were dilated with $5 \%$ ophthalmic tropicamide $(0.5 \%)$ and atropine sulfate $(0.04 \%)$. ERGs were recorded in a darkened room. Stimuli were presented using a small LED Ganzfeld stimulator positioned directly in front of the recording eye. Amplitudes and latencies were calculated for the A- and $\mathrm{B}$-waves as a function of luminance for the dark-adapted retina as an indicator of rodmediated function. In addition, light-adapted (cone) ERGs and $30 \mathrm{~Hz}$ flicker responses were recorded as an indication of cone-mediated visual function.

Light microscopic immunohistochemistry of the inner ear. Sedated (Avertin (2,2,2-tribromethanol), $300 \mu \mathrm{g} / \mathrm{gm} \mathrm{BW}$, i.p.) mice were transcardially perfused with PBS, followed by $4 \%$ paraformaldehyde in $0.1 \mathrm{M}$ PBS. The cochleae were decalcified $\left(0.12 \mathrm{M}\right.$ EDTA, pH 7.0, $\left.24 \mathrm{~h}, 23^{\circ} \mathrm{C}\right)$, dehydrated in a graded ethanol series, embedded in paraffin (Paraplast), and sectioned $(5 \mu \mathrm{m})$ in the mid-modiolar plane. Immunohistochemistry was performed using the avidin-biotin complex technique using a rabbit polyclonal antibody for Kir4.1 (Alomone Laboratories) and a mouse anti-quail antibody for MelEM (DHSB, University of Iowa, Iowa City, IA).

Light microscopic assessment of the retina. Retinas were removed and fixed. Radial sections that spanned the optic disc to the peripheral edge were taken from the temporal portion of each retina within $2 \mathrm{~mm}$ of the macula. Sections were cryoprotected in $25 \%$ sucrose overnight before they were embedded in OCT (Ted Pella), then cut at a thickness of $10 \mu \mathrm{m}$ on a cryostat (Leica), mounted, stained, and viewed under the microscope.

Transmission electron microscopy. The fixed cochleae were dehydrated through a graded series of ethanol and propylene oxide before infiltration and embedding in plastic resin (EmBed 812, EMS). Mid-modiolar thin sections $(70 \mathrm{~nm})$ were placed on formvar-coated copper slot grids and counterstained with uranyl acetate and lead citrate. Sections were viewed on a JEOL $1010 \times$ transmission electron microscope.

\section{Results}

The tyrosinase (tyr) enhancer mouse with attenuated diphtheria toxin $\mathrm{A}(D T-A)$ gene is restricted to neural crest-derived pigment cells, and the TG mice ( $\operatorname{tyr}(h s 3.6 / 6.1)-D T-A)$, heretofore denoted as $(t y r-D T-A)$, have been shown to have no pigmented hair (Camacho-Hubner and Beermann, 2001). Although inconclusive, it has been suggested that ICs are melanocytes of neural crest origin (Steel and Barkway, 1989). We surmised that tyr-DT-A mice may have compromised $\mathrm{StV}$ architecture, which may raise the hearing threshold. Response to Preyer's reflex was negative for the tyr-DT-A mice (for 28510 - to 16-week-old TG mice) compared with the WT (C57) mice. To test the extent of hearing loss, ABR measurements were performed. As shown in Figure 1, $A$ and $B$, age-matched WT mice exhibited the characteristic ABR waveform at sound pressure levels as low as $20-30 \mathrm{~dB}$. The ABR waveforms were not observed in $t y r-D T-A$ mice for any of the sound stimuli, even at $100 \mathrm{~dB}$ and at all frequencies tested. Similarly, DPOAE testing showed no difference between the responses of tyr-DT-A mice and the noise floor, whereas the control groups showed robust responses (Fig. 1C). At 3 weeks of age, the magnitude of the EP of $t y r-D T-A$ mice was variable but not significant from the age-matched controls. Moreover, there was complete loss of the EP in the tyr-DT-A mice by 16 weeks, which parallels the hearing deficiency (Fig. 1D).

The genesis of hearing occurs at $\sim 2-3$ weeks, and at this stage, the cochlear tissues of the TG and control mice appear normal, with the exception of slight and insignificant decreases in the width of the StV (Fig. $2 A-D$ ). Examination of the stria at higher magnification indicated normal BC as well as MC bodies, suggesting that the reduced width resulted from the decrease in area of the ICs. By postnatal week 16, the width of the StV of the tyr-DT- $A$ at different levels had plummeted and there were some sections in which MC nuclei were located in unusually close apposition to the BCs (Fig. 2). By week 16, the tyr-DT-A mice began to lose outer hair cells at the basal turn of the cochlea. The cellular architecture in the lateral wall varied. In some turns, the spiral ligament appeared normal, and the stria had a normal density and thickness. In other turns, the stria had atrophied, consisting of a layer of squamous epithelial cells overlaying remnants of capillaries and BCs. In these turns, the spiral ligament often showed that extracellular matrix had replaced many of the fibrocytes. Comparison of the strial fine structure in the 4 month WT 

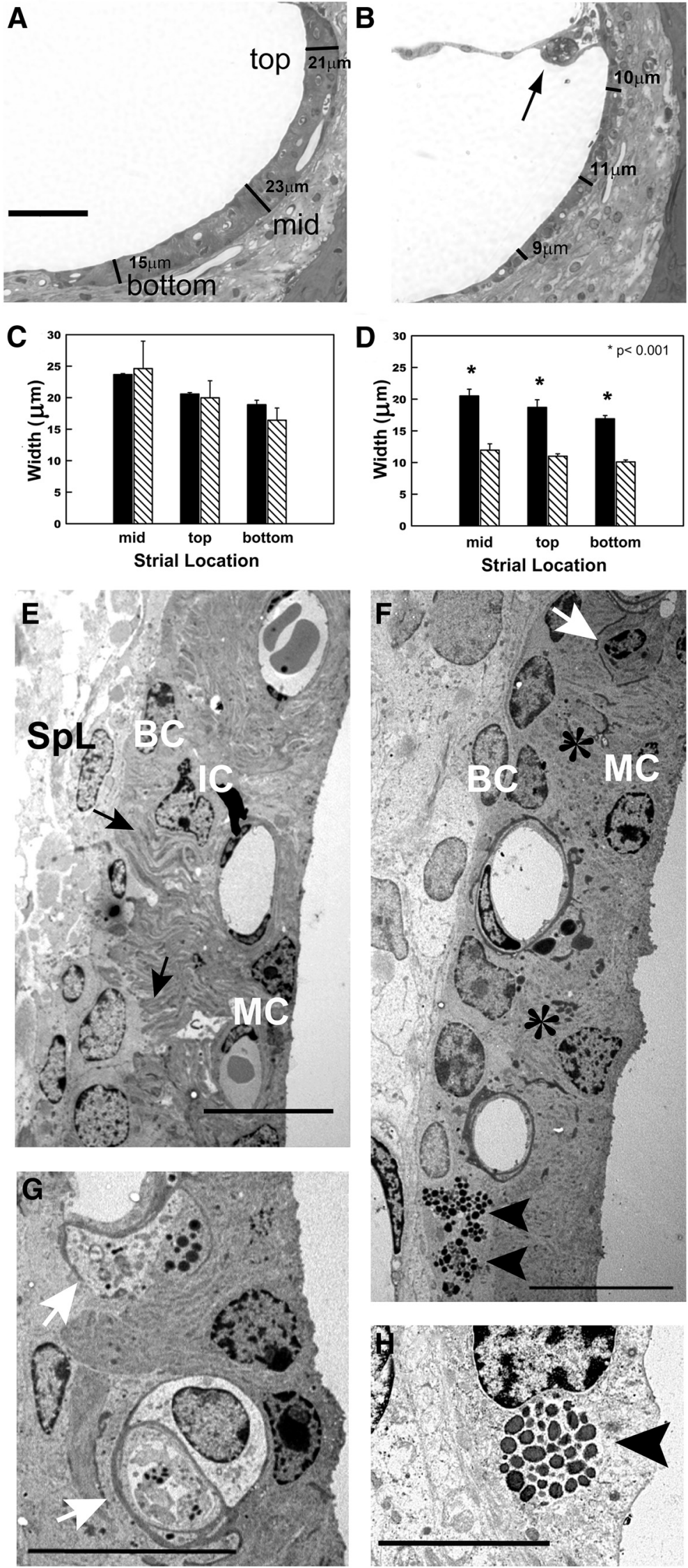

Figure 2. StV morphology at 16 weeks of age. $\boldsymbol{A}$, The $\mathrm{C} 57 \mathrm{StV}$ shows a normal appearance in which the basolateral processes of MCs interdigitate with cytosolic processes of ICs. The top, mid, and bottom locations at which strial thickness were measured (black lines). $\boldsymbol{B}$, The StV of tyr-DT-A mice is visibly thinner. A consistent feature in the TG mice was cellular debris adjacent to Reissner's and tyr-DT-A mice (Fig. $2 E, F$ ) confirmed that the decreased strial width in the tyr$D T-A$ mice was due to loss of the interdigitations among the MC and IC processes (Fig. 2E, arrow). The $\mathrm{MC}$ in the tyr-DT-A mice lacked basolateral processes, giving them an appearance similar to thick cuboidal epithelial cells (Fig. 2F, asterisks). Evidence of disruption of strial homeostasis was the presence of excessive melanin granules present not only in the IC and BC (Fig. 2F,H, arrowheads), but also in the MC (Fig. 2G,H). The few remaining ICs were enclosed by a thick extracellular membrane (Fig. 2F, white arrow). At higher magnification (Fig. $2 G, H)$, evidence of autophagy in these ICs could easily be detected.

MelEM represents the $\alpha$-subunits of glutathione S-transferase and is derived utterly from neural crest cells and not of those from the neural retina pigmented cells (Nataf et al., 1993; Uehara et al., 2009). The enzyme is activated when the migrating neural crest cell reaches the subectodermal mesenchyme. We tested whether ICs migrate to the $\mathrm{StV}$ in the tyr$D T-A$ mice. In control C57 mice, MelEM was never noted in the stria at 3 weeks of age (Fig. 3). In contrast, a strong expression of MelEM was seen in the stria of 3 -week-old tyr-DT-A mice, and it persisted up to 7 weeks, when it was faint. By 16 weeks, MelEM expression was not observed, perhaps partly because of the loss of melanocytes and/or thinning of the StV resulting from loss of basolateral processes of the MCs.

The prevailing model for the generation of the EP asserts that outflow of $\mathrm{K}^{+}$ from ICs into the IS is conferred by Kir4.1

\section{$\leftarrow$}

membrane (arrow). Scale bar, $50 \mu \mathrm{m}$. SpL, Spiral ligament. Strial width at 3 weeks and 16 weeks of age. C, No significant difference in strial width exists between 57 (black bar) and tyr-DT-A (hatched bar) mice at 3 weeks of age. C, D, Width of the StV in 4-month-old tyr-DT-A mice is significantly thinner than that of the age-matched $(57$ mouse $(p<0.001)$. $\boldsymbol{E}$, The StV of a 4-month-old WT (C57) mouse shows MCs with the expected apically located nucleus and basal processes that interdigitate with processes of medially located ICs. The interdigitations appear as light and dark striations (arrows). BCs underlie the ICs. Fibrocytes and extracellular matrix of the spiral ligament (SpL) abut the abluminal border of the basal cell. $\boldsymbol{F}$, The StV of the 4-month-old tyr-DT-A mouse is visibly thinner, and the striated pattern of $M C s / I C$ interdigitations is absent (asterisks). Few ICs are noted, many of which are in stages of autophagy and surrounded by basement membranes (white arrow). Clusters of melanin (arrowheads) are noted in the few ICs and BCs. G, Higher magnification showing degenerating ICS surrounded by basement membranes (white arrows). $\boldsymbol{H}, \mathrm{MC}$ shows the unusual incorporation of melanin granules (arrowhead). Scale bars: $\boldsymbol{E}-\mathbf{G}, 10 \mu \mathrm{m} ; \boldsymbol{H}, 5 \mu \mathrm{m}$. 


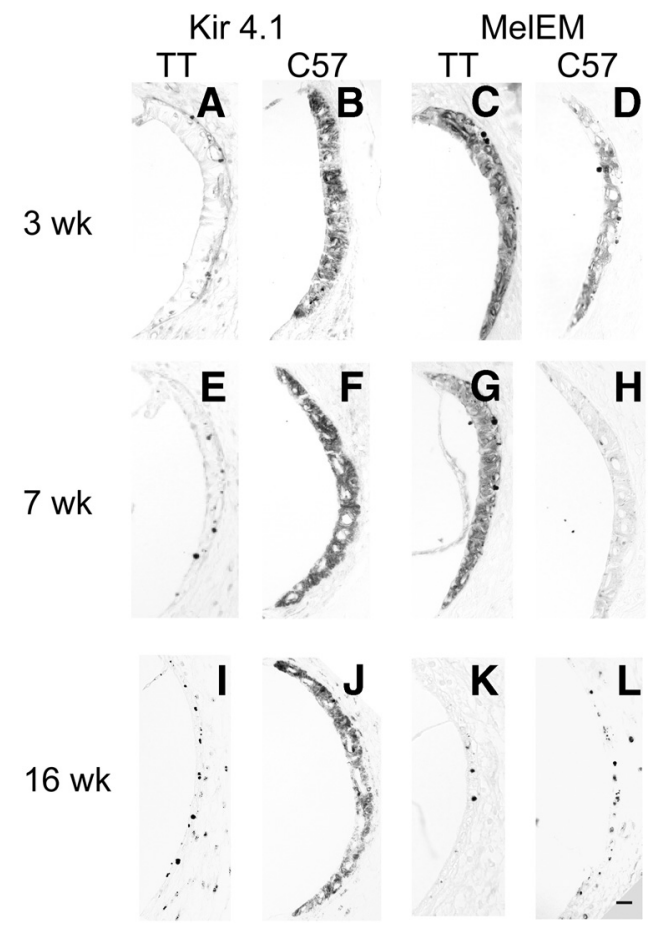

Figure 3. Immunoreactivity for Kir4.1 and MelEM as a function of age. $\boldsymbol{A}, \boldsymbol{B}$, With the exception of a low level of immunoreactivity in the abluminal side of the 3-week-old stria, Kir4. 1 is not expressed in the tyr-DT-A (TG/TT) mice. C, D, MelEM, a protein specific to immature neural crest-derived melanoblasts, is present in high levels in the tyr-DT-A mouse at 3 weeks of age compared with the age-matched controls. $\boldsymbol{E}, \boldsymbol{F}$, Reactivity for Kir4. 1 is noted at all ages in the $C 57$ $\mathrm{StV}$, with the most intense expression present at 7 weeks of age. $\mathbf{G}, \boldsymbol{H}$, MelEM continues to be present in high levels in the tyr-DT-A mouse at 7 weeks of age. $I, J$, No Kir4. 1 reactivity is noted at 16 weeks of age. $\boldsymbol{K}, \boldsymbol{L}$, MelEM expression decreases in the $\mathbf{C 5 7}$ as a function of age. The expression is highest at 2 weeks of age (data not shown) and decreases to a low level by 7 weeks of age, with no expression of the protein at 16 weeks of age. Scale bar, $20 \mu \mathrm{m}$.

channel being expressed at the apical aspects of ICs (Marcus et al., 2002) and that mutations associated with the channel result in sensorineural hearing loss (Scholl et al., 2009). We examined whether melanocytes that migrate to the stria are decorated with Kir4.1. As shown in Figure 3, Kir4.1 expression in the spiral ligament was equivalent to background staining. Traces of Kir4.1 expression can be seen in 3-week-old tyr-DT-A mice stria. In contrast, there was strong expression of Kir4.1 in the C57 mouse, regardless of age (Fig. 3 ).

The vestibular dark cells in the vestibular labyrinth and the strial MCs share common traits and functions (Wangemann, 2002). Indeed, a potential of $\sim 5 \mathrm{mV}$ has been reported in the vestibular labyrinth. Thus, it is not uncommon that malfunction of $\mathrm{K}^{+}$homeostasis in the cochlear duct results in vestibular defect as well (Delpire et al., 1999; Flagella et al., 1999). Moreover, whereas vestibular dark cells form single-layered epithelia, MCs form one cellular component of the $\mathrm{StV}$. We performed gross evaluation of vestibular functions using swimming performance and balance test as described in our previous studies (Dou et al., 2004). WT C57 and tyr-DT-A mice (5- to 16-week-old) yielded similar scores for the swim and balance test (data not shown).

The retina pigmented epithelium consists of a monolayer of pigmented cells at the back of the eye between the neuroretina and the choroids. The retina pigmented epithelium is recognized as cells of a different kind compared with neural crest-derived melanocytes (Simo et al., 2010; Bharti et al., 2011). We examined the functional status of the retina in 8- to 16-week-old tyr-DT-A mice and their age-matched controls. As demonstrated in Figure 4 , there were no discernible differences in retinal responses between the TG and control mice, including responses to light intensities, cone functions, and light sensitivity. Consistent with the functional data, the morphology of the retina in control and TG mice was noticeably similar (Fig. 4).

\section{Discussion}

Almost six decades after the EP was first reported and described as the powerhouse for cochlear transduction (Von Bekesy, 1952), details of the mechanisms of its generation and maintenance have remained an enigma. Recent reports, including the present study, are revealing not only the cellular components of the $\mathrm{StV}$ that confer the EP, but also the contribution of the cellular syncytia and the $\mathrm{K}^{+}$channels and transporters/pumps that operate to orchestrate unidirectional (basal to apical) flux of $\mathrm{K}^{+}$to produce the EP (Salt et al., 1987; Wangemann, 2006; Nin et al., 2008). In this study, we have used genetic and molecular strategies to confirm the indispensable role of ICs in the generation of the EP. Additionally, by ratifying that ICs are indeed melanocytes and that the tyrosinase promoter is restricted to ICs in the inner ear, the findings revealed serendipitously an untapped genetic manipulation approach that can be used to study cell-specific ion channels/transporters in ICs. Moreover, the use of the tissuespecific tyrosinase promoter to drive expression of a suicide gene in ICs halts the final migration and differentiation of these cells from the neural crest. Meanwhile, the expression of MelEM in ICs precedes the onset of pigment synthesis, followed by a downregulation in fully differentiated melanocytes. Activation of the $D T$ gene produced significantly decreased strial width resulting from the loss of ICs and retraction of MC processes. The expression of Kir4.1 occurs at low levels during the final stages of migration and differentiation of the ICs. Finally, analyses of retinal function in the tyr-DT-A mice demonstrate that the tyrosinase promoter can be used to genetically modify neural crest-derived melanocytes without compromising the retina.

The width of the StV of $t y r-D T-A$ mice at 3 weeks after birth was comparable with their C57 controls. The EPs were reasonably higher than at later stages (e.g., at weeks 8-16). The most likely explanation for these findings is that neural crest-derived melanoblasts migrate to the StV before activation of the Tyr gene and synthesis of melanin in the inner ear, and that the role of ICs as pigment producers is independent of their function as generators of the EP. Evidently, StV of albino animals have been found to be functional in producing the EP and have intact hearing (Steel and Barkway, 1989; Conlee and Bennett, 1993; Gill and Salt, 1997), suggesting that perhaps, in the inner ear, expression of Kir4.1 precedes activation of the Tyr gene. Hence, for the mouse model used in this study, the process of the EP generation may occur before IC death. The retraction of the interdigitations of ICs from MCs increases the IS, abolishing/reducing its impedance. Additionally, loss of Kir4.1 channels is expected to abolish the EP (Marcus et al., 2002). Finally, because retinal functions appear intact in the tyr-DT-A mice, these findings dovetail well with reports that retina pigmented epithelium and pigment synthesis are of a different embryonic origin and biochemistry (Simo et al., 2010).

The three cells in the StV can be categorized into two because BCs are electrically coupled to ICs by gap junctions (Kikuchi et al., 1995). Because the IC-BC cellular unit would be endowed with the tyrosinase promoter, it is conceivable that selective genetic manipulations of $\mathrm{K}^{+}$channels suspected to be expressed in 
A
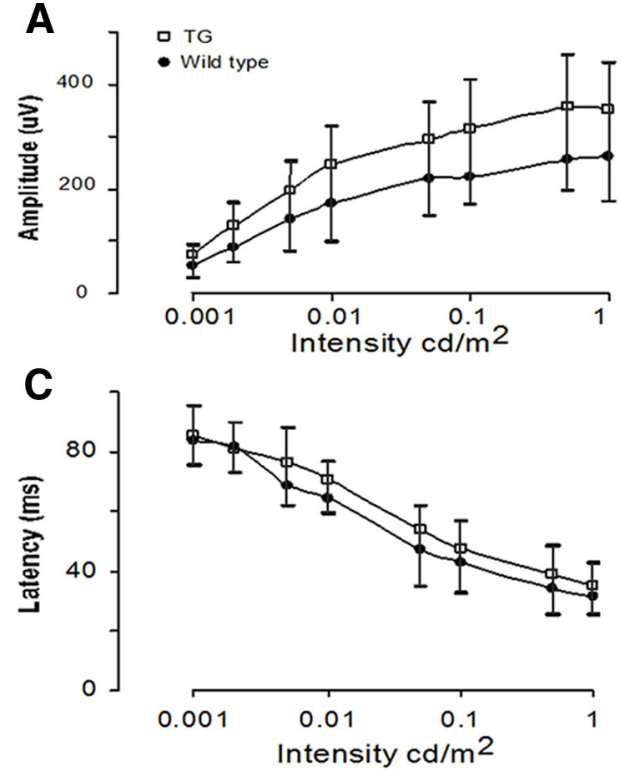

$\mathbf{E}$
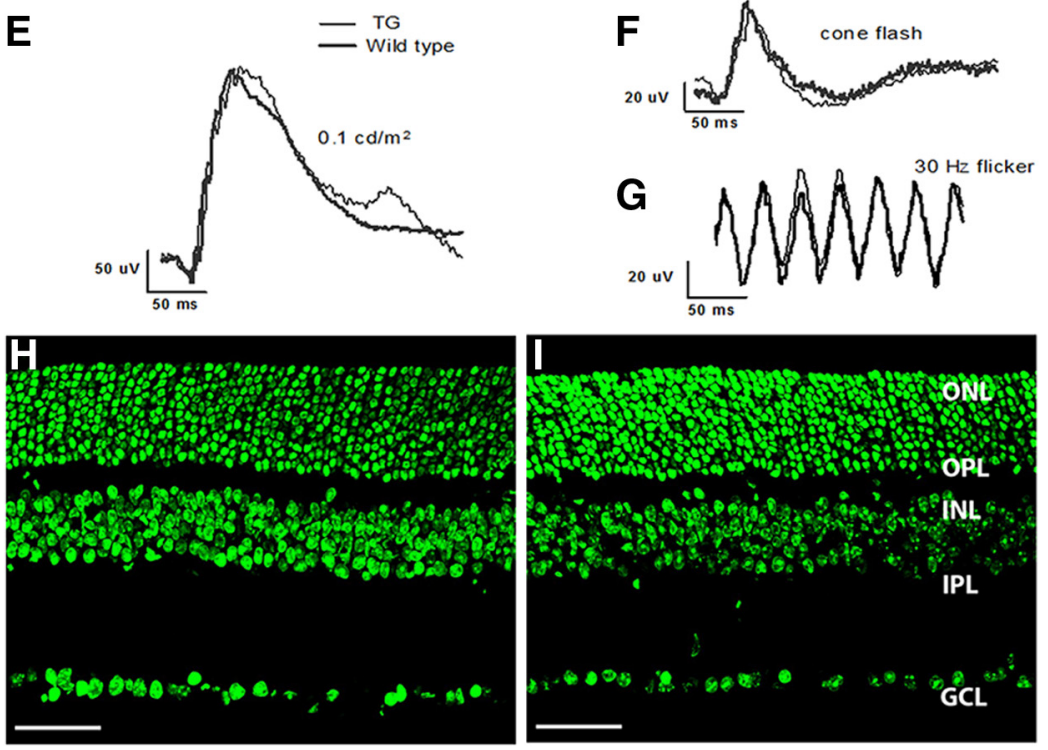

Figure 4. ERG results comparing WT and TG mice. $\boldsymbol{A}$, Amplitude of the dark-adapted flash ERG B-wave as a function of stimulus intensity. Open squares represent TG/TT mice; filled circles represent C57. Error bars indicate SD. The amplitudes from TG and C57 mice are not significantly different. $\boldsymbol{B}$, Amplitudes of the light-adapted (cone) and $30 \mathrm{~Hz}$ flicker ERG. The 57 and TG amplitudes are not significantly different. C, Latencies for the dark-adapted, ERG B-wave. TG and C57 latencies do not differ significantly. D, Latencies for the cone B-wave and implicit time for the $30 \mathrm{~Hz}$ flicker response. The TG and $\mathrm{C} 57$ latencies do not differ. E-G, Sample waveforms from TG (light lines) and 57 (heavy lines) mice. The waveforms from TG and 57 mice under dark-adapted, lightadapted (cone), and $30 \mathrm{~Hz}$ flicker conditions are nearly identical. $\boldsymbol{H}, \boldsymbol{I}$, Histology of the retina of $\mathrm{C57}(\boldsymbol{H})$ and $\mathrm{TG}$ mice $(\boldsymbol{I})$ were similar. ONL, Outer nuclear layer; $\mathrm{OPL}$, outer plexiform layer; INL, inner nuclear layer; IPL, inner plexiform layer; GCL, ganglion cell layer. capillary beds in the TG mouse model may be necessary to address this caveat in future studies.

\section{References}

Barhanin J, Lesage F, Guillemare E, Fink M, Lazdunski M, Romey G (1996) K(V)LQT1 and lsK ( $\operatorname{minK})$ proteins associate to form the $\mathrm{I}(\mathrm{Ks})$ cardiac potassium current. Nature 384: 78-80. CrossRef Medline

Bharti K, Miller SS, Arnheiter H (2011) The new paradigm: retinal pigment epithelium cells generated from embryonic or induced pluripotent stem cells. Pigment Cell Melanoma Res 24:21-34. CrossRef Medline

Camacho-Hübner A, Beermann F (2001) Increased transgene expression by the mouse tyrosinase enhancer is restricted to neural crest-derived pigment cells. Genesis 29:180187. CrossRef Medline

Conlee JW, Bennett ML (1993) Turn-specific differences in the endocochlear potential between albino and pigmented guinea pigs. Hear Res 65:141-150. CrossRef Medline

Delpire E, Lu J, England R, Dull C, Thorne T (1999) Deafness and imbalance associated with inactivation of the secretory $\mathrm{Na}-\mathrm{K}-2 \mathrm{Cl}$ co-transporter. Nat Genet 22:192-195. CrossRef Medline

Dou H, Vazquez AE, Namkung Y, Chu H, Cardell EL, Nie L, Parson S, Shin HS, Yamoah EN (2004) Null mutation of alpha1D $\mathrm{Ca}^{2+}$ channel gene results in deafness but no vestibular defect in mice. J Assoc Resin Otolaryngol 5:215-226. CrossRef Medline

Erway LC, Willott JF, Archer JR, Harrison DE (1993) Genetics of age-related hearing loss in mice: I. Inbred and F1 hybrid strains. Hear Res 65:125-132. CrossRef Medline

Flagella M, Clarke LL, Miller ML, Erway LC, Giannella RA, Andringa A, Gawenis LR, Kramer J, Duffy JJ, Doetschman T, Lorenz JN, Yamoah EN, Cardell EL, Shull GE (1999) Mice lacking the basolateral Na-K-2Cl cotransporter have impaired epithelial chloride secretion and are profoundly deaf. J Biol Chem 274 : 26946-26955. CrossRef Medline

Gill SS, Salt AN (1997) Quantitative differences in endolymphatic calcium and endocochlear potential between pigmented and albino guinea pigs. Hear Res 113:191-197. CrossRef Medline

Hibino H, Nin F, Tsuzuki C, Kurachi Y (2010) How is the highly positive endocochlear potential formed? The specific architecture of the stria vascularis and the roles of the iontransport apparatus. Pflugers Arch 459:521533. CrossRef Medline

Kikuchi T, Kimura RS, Paul DL, Adams JC this cellular complex can be achieved using the promoter. Similar strategies may be adapted for cell-specific genetic alteration of ion transporters and channels in MCs. The chloride channel $\mathrm{ClC}-\mathrm{Kb}$ promoter is distinctly expressed in MCs and can be used to drive MC-specific expression of genes (Sage and Marcus, 2001; Kobayashi et al., 2002). A cautionary note from the conclusions of the present findings is that the histological data indicated loss of blood vessels in the StV of the tyr-DT-A mice. Whereas the decrease in capillary beds may result from loss of ICs, it is conceivable, albeit unlikely, that the loss of IC function is secondary, or at least worsened, by loss of vascularization. Assessment of the differences in vascularization of other organ systems with robust
(1995) Gap junctions in the rat cochlea: immunohistochemical and ultrastructural analysis. Anat Embryol 191:101-118. Medline

Kobayashi K, Uchida S, Okamura HO, Marumo F, Sasaki S (2002) Human CLC-KB gene promoter drives the EGFP expression in the specific distal nephron segments and inner ear. J Am Soc Nephrol 13:1992-1998. CrossRef Medline

Marcus DC, Wu T, Wangemann P, Kofuji P (2002) KCNJ10 (Kir4.1) potassium channel knockout abolishes endocochlear potential. Am J Physiol

Murillo-Cuesta S, Contreras J, Zurita E, Cediel R, Cantero M, Varela-Nieto I, Montoliu L (2010) Melanin precursors prevent premature age-related and noise-induced hearing loss in albino mice. Pigment Cell Melanoma Res 23:72-83. CrossRef Medline Cell Physiol 282:C403-C407. CrossRef Medline 
Nataf V, Mercier P, Ziller C, Le Douarin NM (1993) Novel markers of melanocyte differentiation in the avian embryo. Exp Cell Res 207:171-182. CrossRef Medline

Nie L, Feng W, Diaz R, Gratton MA, Doyle KJ, Yamoah EN (2005) Functional consequences of polyamine synthesis inhibition by L-alpha-difluoromethylornithine (DFMO): cellular mechanisms for DFMO-mediated ototoxicity. J Biol Chem 280:15097-15102. CrossRef Medline

Nin F, Hibino H, Doi K, Suzuki T, Hisa Y, Kurachi Y (2008) The endocochlear potential depends on two $\mathrm{K}^{+}$diffusion potentials and an electrical barrier in the stria vascularis of the inner ear. Proc Natl Acad Sci U S A 105:1751-1756. CrossRef Medline

Sage CL, Marcus DC (2001) Immunolocalization of ClC-K chloride channel in strial marginal cells and vestibular dark cells. Hear Res 160:1-9. CrossRef Medline

Salt AN, Melichar I, Thalmann R (1987) Mechanisms of endocochlear potential generation by stria vascularis. Laryngoscope 97:984-991. Medline

Scholl UI, Choi M, Liu T, Ramaekers VT, Häusler MG, Grimmer J, Tobe SW, Farhi A, Nelson-Williams C, Lifton RP (2009) Seizures, sensorineural deafness, ataxia, mental retardation, and electrolyte imbalance (SeSAME syndrome) caused by mutations in KCNJ10. Proc Natl Acad Sci U S A 106:5842-5847. CrossRef Medline

Simó R, Villarroel M, Corraliza L, Hernández C, Garcia-Ramírez M (2010) The retinal pigment epithelium: something more than a constituent of the blood-retinal barrier-implications for the pathogenesis of diabetic retinopathy. J Biomed Biotechnol 2010:190724. CrossRef Medline

Steel KP, Barkway C (1989) Another role for melanocytes: their importance for normal stria vascularis development in the mammalian inner ear. Development 107:453-463. Medline

Takeuchi S, Ando M, Kakigi A (2000) Mechanism generating endocochlear potential: role played by intermediate cells in stria vascularis. Biophysical J 79:2572-2582. CrossRef Medline

Uehara S, Izumi Y, Kubo Y, Wang CC, Mineta K, Ikeo K, Gojobori T, Tachibana M, Kikuchi T, Kobayashi T, Shibahara S, Taya C, Yonekawa H, Shiroishi T, Yamamoto H (2009) Specific expression of Gsta4 in mouse cochlear melanocytes: a novel role for hearing and melanocyte differentiation. Pigment Cell Melanoma Res 22:111-119. CrossRef Medline

Von Bekesy G (1952) Resting potentials inside the cochlear partition of the guinea pig. Nature 169:241-242. CrossRef Medline

Wang X, Levic S, Gratton MA, Doyle KJ, Yamoah EN, Pegg AE (2009) Spermine synthase deficiency leads to deafness and a profound sensitivity to alpha-difluoromethylornithine. J Biol Chem 284:930-937. CrossRef Medline

Wangemann P (2002) $\mathrm{K}^{+}$cycling and the endocochlear potential. Hear Res 165:1-9. CrossRef Medline

Wangemann P (2006) Supporting sensory transduction: cochlear fluid homeostasis and the endocochlear potential. J Physiol 576:11-21. CrossRef Medline 